Arq. Bras. Med. Vet. Zootec., v.67, n.2, p.511-518, 2015

\title{
Efeito do ambiente ruminal sobre a degradabilidade de colmos da cana-de-açúcar
}

\author{
[Effect of the rumen environment on sugarcane stems degradability] \\ M.N. Pereira ${ }^{1}$, H.N. Costa ${ }^{1}$, R.P. Melo ${ }^{1}$, M.L. Chaves ${ }^{1}$, R.F. Lima ${ }^{1}$, R.A.N. Pereira ${ }^{2}$ \\ ${ }^{1}$ Universidade Federal de Lavras - UFLA - Lavras, MG \\ ${ }^{2}$ Empresa de Pesquisa Agropecuária de Minas Gerais - Epamig - Lavras, MG
}

\begin{abstract}
RESUMO
Avaliou-se o efeito do ambiente ruminal sobre a degradação da FDN de 12 cultivares de cana. As dietas continham: $87,1 \%$ de cana (Cana) ou $42,0 \%$ de cana e $58,0 \%$ de concentrado com milho (Milho) ou polpa cítrica (Polpa). Seis vacas com cânula ruminal formaram quadrados latinos 3x3. Por 11 dias de cada período experimental, o consumo de matéria seca foi fixado em $1,2 \%$ do peso vivo. No dia 12 , baixo $\mathrm{pH}$ ruminal foi induzido no Milho e na Polpa por infusão intrarruminal de milho ou polpa cítrica. Simultaneamente, ureia foi adicionada ao rúmen em todos os tratamentos. Sacos de náilon contendo os cultivares foram incubados por 24h nos dias 11 e 12 . O pH ruminal no dia 11 foi 7,01 e $\mathrm{NH}_{3}$ foi 3,4, 4,4 e 6,2mg/dL para Cana, Milho e Polpa, respectivamente. $\mathrm{O}$ pH no dia 12 foi 6,98 para Cana, 6,49 para Milho e 6,04 para Polpa, e $\mathrm{NH}_{3}$ foi $13,0 \mathrm{mg} / \mathrm{dL}$. Para Cana, a degradabilidade ruminal da FDN foi $21 \%$ no dia 11 e $28 \%$ no dia 12; para Milho e Polpa esta foi ao redor de $21 \%$ em ambos os dias. O ordenamento dos cultivares por degradabilidade ruminal da FDN foi similar nos ambientes ruminais distintos.
\end{abstract}

Palavras-chave: amido, digestibilidade, efeito associativo, fibra, polpa cítrica

\begin{abstract}
The effect of the rumen environment on NDF degradability of 12 sugarcane cultivars was evaluated. Diets contained: $87.1 \%$ of sugarcane (Cane) or $42.0 \%$ of sugarcane and $58.0 \%$ of concentrates with corn (Corn) or citrus pulp (Citrus). Six rumen cannulated cows formed 3x3 Latin Squares. For 11 days of each experimental period, the intake of dry matter was fixed at 1.2\% of body weight. On day 12, low ruminal pH was induced on Corn and Citrus by pulse dosing corn or citrus pulp into the rumen. Simultaneously, urea was added to the rumen in all treatments. Nylon bags containing the cultivars were incubated for 24 $h$ on the $11^{\text {th }}$ and $12^{\text {th }}$ days. Rumen $\mathrm{pH}$ on day 11 was 7.01 and $\mathrm{NH}_{3}$ was 3.4, 4.4 and $6.2 \mathrm{mg} / \mathrm{dl}$ for Cane, Corn and Citrus, respectively. Ruminal pH on day 12 was 6.98 for Cane, 6.49 for Corn and 6.04 for Citrus and $\mathrm{NH}_{3}$ was $13.0 \mathrm{mg} / \mathrm{dl}$. For Cane, ruminal $\mathrm{NDF}$ degradability was $21 \%$ on day 11 and $28 \%$ on day 12, for Corn and Citrus it was around $21 \%$ in both days. The ranking of cultivars based on ruminal NDF degradability was similar in distinct rumen environments.
\end{abstract}

Keywords: associative effect, citrus pulp, digestibility, fiber, starch

\section{INTRODUÇÃO}

A correlação entre o teor de fibra em detergente neutro (FDN) e a digestibilidade da matéria seca no rúmen é negativa e alta na cana-de-açúcar (Pate e Coleman, 1975; Teixeira et al., 2014). Como a digestibilidade da FDN da cana-deaçúcar é baixa (Corrêa et al., 2003), a seleção de cultivares que conciliam o baixo conteúdo de FDN à alta digestibilidade deste nutriente, pode resultar em ganho em desempenho animal. Existem evidências da ocorrência de variabilidade entre cultivares de cana-de-açúcar na degradabilidade ruminal da FDN (Molina, 1999) e na digestibilidade aparente da FDN no trato digestivo total (Pate, 1981).

Recebido em 24 de abril de 2014

Aceito em 9 de fevereiro de 2015

E-mail: mpereira@dzo.ufla.br 
A cana-de-açúcar tem potencial para ser utilizada em dietas para ruminantes leiteiros de alto desempenho (Corrêa et al., 2003). Nesses casos, a utilização de alimentos concentrados é necessária para suprir a alta demanda nutricional. No entanto, carboidratos dietéticos de degradação rápida no rúmen têm efeito associativo negativo sobre a degradação ruminal da fibra de forrageiras, sendo a queda na digestão dependente do tipo da forragem (Grant e Mertens, 1992). Se a magnitude da inibição na degradabilidade ruminal da cana-de-açúcar for suficiente para eliminar diferenças de degradabilidade entre cultivares, a seleção de plantas com maior velocidade de degradação da fibra no rúmen não seria aplicável a sistemas de produção que adotam altas inclusões de alimentos concentrados na dieta.

A queda na degradação ruminal da fibra em dietas ricas em energia poderia ser atenuada por mudança na natureza química da fração de carboidratos não fibrosos, por substituição de concentrados ricos em amido por subprodutos fibrosos ricos em pectina e fibra (ex.: polpa de citros). A fermentação tanto da pectina quanto da celulose foi inibida em baixo $\mathrm{pH}$ in vitro, enquanto a digestão do amido não foi afetada (Marounek et al., 1985). Por evitar uma queda acentuada no $\mathrm{pH}$ ruminal in vivo, a pectina pode não inibir a digestão da fibra tanto quanto açúcares e amidos de degradação rápida. A substituição de amido por pectina também poderia ser benéfica pelo fato de microrganismos ruminais digestores de pectina também terem a capacidade de utilizar hemicelulose como substrato (Osborne e Dehority, 1989). Se a substituição de amido por pectina reduzir a magnitude dos efeitos associativos negativos da presença de amido no rúmen sobre a digestão ruminal da fibra, essa estratégia alimentar seria efetiva em situações que visam à alta produção por animal e nas quais existe disponibilidade de canas com alto potencial de degradação da fibra no rúmen.

O objetivo deste experimento foi avaliar a ocorrência de efeitos associativos negativos da presença de amido no rúmen bem como o efeito da substituição de amido por fibra e pectina de polpa cítrica sobre a degradação ruminal da FDN de cultivares de cana-de-açúcar, caracterizando a resposta à mudança na química do ambiente ruminal. $\mathrm{O}$ efeito da variação química sobre a degradação ruminal da cana foi avaliado em $\mathrm{pH}$ ruminal alto e amônia baixa ou $\mathrm{pH}$ baixo e amônia alta, representativo de ambientes ruminais em que o aporte nutricional é baixo ou alto, respectivamente. $\mathrm{O}$ efeito do ambiente ruminal sobre o ordenamento dos cultivares por degradabilidade ruminal da fibra foi avaliado.

\section{MATERIAL E MÉTODOS}

Seis vacas não lactantes com cânula ruminal formaram dois quadrados latinos $3 \times 3$, com períodos de 14 dias. Os animais foram alimentados com dieta completa (Tab. 1) fornecida uma vez por dia, às 8h30. Por um período pré-experimental de 10 dias, uma dieta controle foi fornecida ad libitum para definir a menor ingestão diária entre os animais. O menor consumo proporcional ao peso vivo foi utilizado como meta de consumo para todos os tratamentos, visando induzir alto $\mathrm{pH}$ ruminal. As dietas foram fornecidas a $1,2 \%$ do peso vivo, e não foram observadas sobras alimentares ao longo do experimento.

$\mathrm{Na}$ manhã do $12^{\mathrm{o}}$ dia de cada período experimental (D12), baixo $\mathrm{pH}$ ruminal foi induzido por pulso via cânula ruminal de $0,8 \%$ do peso vivo de milho maduro moído fino, no tratamento Milho, ou a mesma quantidade de polpa de citros peletizada, no tratamento Polpa. Simultaneamente, $0,02 \%$ do peso vivo de ureia foi adicionada ao rúmen nos três tratamentos.

Uma amostra de 12 colmos de cana-de-açúcar foi obtida para obter variabilidade na dureza do colmo (Tab. 2). Os colmos foram triturados e, posteriormente, desidratados em estufa ventilada a $55^{\circ} \mathrm{C}$ por $72 \mathrm{~h}$. Após a pré-secagem, parte das amostras foi moída em peneira com crivo de $1 \mathrm{~mm}$ em moinho do tipo Thomas Willey para realização das análises bromatológicas e a outra parte foi moída em peneira com crivo de $5 \mathrm{~mm}$ para determinação da degradabilidade ruminal in situ. 
Tabela 1. Composição em ingredientes e em nutrientes das dietas consumidas nos tratamentos Cana, Milho e Polpa

\begin{tabular}{lccc}
\hline & Cana & Milho & Polpa \\
\hline & & $\%$ MS & \\
Cana-de-açúcar & 87,0 & 42,0 & 42,8 \\
Farelo de soja & 6,7 & 6,7 & 6,7 \\
Ureia & 2,4 & 1,2 & 1,4 \\
Milho maduro moído fino & & 46,2 & \\
Polpa cítrica peletizada & 3,9 & 3,7 & 1,7 \\
Minerais e vitaminas & & & \\
& 9,9 & 11,5 & 10,5 \\
Proteína bruta (PB) & 42,0 & 26,4 & 28,3 \\
Fibra em detergente neutro (FDN) & 40,1 & 19,4 & 19,7 \\
Fibra em detergente neutro oriunda de cana-de-açúcar & 1,1 & 2,4 & 2,8 \\
Extrato etéreo (EE) & 3,9 & 3,4 & 4,4 \\
Cinzas & 43,1 & 56,3 & 54,0 \\
Carboidratos não fibrosos = 100-(PB+FDN+EE+Cinzas) & \multicolumn{2}{c}{$\%$ MN } & 48,9 \\
Matéria seca & 32,9 & 49,2 & 48,2 \\
\hline
\end{tabular}

Tabela 2. Composição dos colmos dos 12 cultivares de cana-de-açúcar

\begin{tabular}{lccccccccc}
\hline & MS $^{1}$ & PB $^{1}$ & EE $^{1}$ & FDN $^{1}$ & Cinzas $^{1}$ & CNF $^{1}$ & DEG MS $^{2}$ & DEG FDN & RES 72 $^{2}$ \\
& $\%$ & $\%$ & $\%$ & $\%$ & $\%$ & $\%$ & $\%$ & $\%$ & $\%$ \\
Caiana amarela & 25,1 & 4,3 & 0,7 & 37,2 & 1,9 & 55,9 & 70,8 & 28,8 & 24,2 \\
CO 413 & 31,2 & 1,3 & 0,6 & 42,1 & 1,5 & 54,5 & 61,4 & 18,0 & 34,4 \\
RB 72454 & 28,1 & 2,3 & 0,7 & 45,7 & 1,9 & 49,4 & 60,6 & 22,2 & 32,8 \\
RB 739359 & 31,0 & 1,7 & 0,4 & 38,0 & 1,6 & 58,4 & 66,6 & 20,9 & 28,7 \\
RB 739735 & 29,9 & 0,7 & 0,7 & 37,9 & 2,1 & 58,6 & 66,6 & 20,8 & 28,1 \\
RB 758540 & 26,6 & 2,0 & 1,3 & 45,5 & 1,4 & 49,8 & 62,2 & 23,3 & 33,6 \\
RB 835089 & 30,1 & 1,3 & 1,3 & 47,8 & 2,6 & 48,3 & 58,8 & 21,9 & 35,4 \\
RB 855536 & 33,1 & 1,3 & 2,3 & 37,0 & 1,2 & 58,2 & 70,3 & 27,5 & 23,8 \\
SP 701143 & 27,1 & 3,2 & 2,8 & 45,7 & 2,4 & 45,9 & 61,9 & 24,1 & 30,9 \\
SP 801836 & 34,9 & 2,7 & 1,5 & 33,6 & 1,1 & 61,0 & 70,7 & 21,1 & 24,9 \\
SP 801842 & 32,1 & 2,5 & 0,7 & 46,6 & 1,5 & 48,7 & 58,0 & 18,9 & 37,0 \\
SP 811520 & 36,3 & 1,7 & 2,9 & 44,8 & 1,0 & 49,6 & 59,4 & 17,7 & 35,5 \\
\hline
\end{tabular}

${ }^{1}$ Matéria seca (MS), proteína bruta $(\mathrm{PB})$, fibra em detergente neutro $(\mathrm{FDN})$, extrato etéreo $(\mathrm{EE})$, carboidratos não fibrosos $(\mathrm{CNF}=$ 100-PB-FDN-EE-Cinzas).

${ }^{2}$ Degradação da MS (DEG MS, \% da MS) e da FDN (DEG FDN, \% da FDN) em 24h de incubação ruminal e resíduo de MS após $72 \mathrm{~h}$ de incubação (RES 72, \% da MS). Média de 18 incubações de cada cultivar em todas as vacas e tratamentos.

O teor de matéria seca dos cultivares foi determinado por secagem da amostra pré-seca a $105^{\circ} \mathrm{C}$ por $24 \mathrm{~h}$. A proteína bruta foi determinada por aparelho de destilação a vapor Microkjeldah, e o extrato etéreo segundo o AOAC. (Official..., 1990). O conteúdo de cinzas foi determinado por incineração a $550^{\circ} \mathrm{C}$ por oito horas. A FDN livre de cinzas foi determinada segundo Van Soest et al. (1991), utilizando-se sulfito de sódio e $\alpha$-amilase. As mesmas metodologias foram utilizadas para análise dos alimentos concentrados e da cana utilizada para alimentação dos animais durante o período experimental.

As amostras de cana foram incubadas no rúmen em todas as vacas em todos os períodos para estimar a degradabilidade in situ. Às 8 h30 da manhã do dia 11 (D11), duas amostras de cada cultivar foram introduzidas no rúmen, uma incubada por $24 \mathrm{~h}$ e outra por $72 \mathrm{~h}$. No D12, outra amostra foi incubada por $24 \mathrm{~h}$ simultaneamente aos pulsos ruminais de milho e ureia, polpa cítrica e ureia ou ureia, nos tratamentos Milho, Polpa ou Cana, respectivamente. 
Para o estudo da degradabilidade in situ, $5 \mathrm{~g}$ de matéria seca dos cultivares foram inseridas em sacos de náilon (Failet, 100\% poliéster) com dimensões de $9 \times 11 \mathrm{~cm}$. Os sacos foram inseridos em sacolas de poliéster, com pesos de $300 \mathrm{~g}$, e estas foram conectadas por um cordão de náilon de aproximadamente $1 \mathrm{~m}$ à cânula ruminal. Após a retirada do rúmen, as amostras foram imersas em água com gelo e, em seguida, foram congeladas. Após descongelamento, os sacos foram lavados em máquina com fluxo de água constante. A matéria seca remanescente da incubação ruminal foi determinada por desidratação em estufa ventilada a $55^{\circ} \mathrm{C}$ por $72 \mathrm{~h}$. A degradação em $24 \mathrm{~h}$ da matéria seca (DEG MS), da FDN (DEG FDN) e da matéria seca não FDN (DEG MSnFDN) e o resíduo de matéria seca após $72 \mathrm{~h}$ de incubação (RES 72) foram calculados.

Amostras de fluido ruminal foram coletadas de 8 h30 do D11 até 8 h30 do dia 13. No D11 as amostras foram coletadas a cada três horas por 24h. No D12, as amostras foram coletadas a cada uma hora nas primeiras seis horas e a cada três horas nas $18 \mathrm{~h}$ restantes. As amostras foram coletadas introduzindo-se um becker no saco ventral do rúmen. $\mathrm{O}$ fluido foi filtrado em gaze, e o pH mensurado imediatamente. A uma amostra de $25 \mathrm{~mL}$ do filtrado foi acrescido $0,5 \mathrm{~mL}$ de ácido tricloroacético a $50 \%$, e a amostra foi congelada para posterior determinação de amônia (Chaney e Marbach, 1962).

A avaliação dos efeitos de tratamento e do ambiente ruminal sobre a DEG MS, a DEG FDN e a DEG MSnFDN foi analisada pelo procedimento MIXED do SAS. Para essas análises de degradação da cana no rúmen foi feita a média dos 12 cultivares em cada vaca em cada período. $\mathrm{O}$ seguinte modelo foi utilizado: $\mathrm{Y}_{\mathrm{ijklm}}=\mu+\mathrm{V}_{\mathrm{i}}+\mathrm{P}_{\mathrm{j}}+\mathrm{T}_{\mathrm{k}}+\mathrm{A}_{\mathrm{l}}+\mathrm{TA}_{\mathrm{kl}}+\mathrm{e}_{\mathrm{ijkl},} \cdot \mathrm{O}$ $\mathrm{pH}$ e a concentração de amônia no fluido ruminal foram analisados como medidas repetidas no tempo. Essas análises foram realizadas separadamente para cada período de $24 \mathrm{~h}$ de coleta de amostras de fluido ruminal. $\mathrm{O}$ seguinte modelo foi utilizado: $\mathrm{Y}_{\mathrm{ijklm}}=\mu+\mathrm{V}_{\mathrm{i}}+\mathrm{P}_{\mathrm{j}}+\mathrm{T}_{\mathrm{k}}+$ $\mathrm{C}_{\mathrm{m}}+\mathrm{TC}_{\mathrm{lm}}+\mathrm{e}_{\mathrm{ijklm}}$. O quadrado médio para a interação entre vaca, período e tratamento foi utilizado como medida de erro para testar o efeito de tratamento. A estrutura de covariância empregada foi aquela com o maior valor para o critério de informação de Akaike. Nos modelos, define-se: $\mathrm{V}_{\mathrm{i}}=$ efeito de vaca $(\mathrm{i}=1$ a 6$) ; \mathrm{P}_{\mathrm{j}}=$ efeito de período $(\mathrm{k}=1$ a 3$) ; \mathrm{T}_{\mathrm{k}}=$ efeito de tratamento ( $1=$ Cana, Milho, Polpa); $A_{1}=$ efeito de ambiente ruminal ( $1=\mathrm{pH}$ alto, amônia baixa, D11; $\mathrm{pH}$ baixo, amônia alta, D12); $\mathrm{TA}_{\mathrm{kl}}=$ interação entre tratamento e ambiente ruminal; $\mathrm{C}_{\mathrm{m}}=$ efeito de tempo de coleta $(\mathrm{m}=$ nove tempos após a alimentação no D11 e 13 tempos após o pulso intrarruminal de concentrados no D12); $\mathrm{TC}_{\mathrm{lm}}=$ interação entre tratamento e tempo de coleta. Dois contrastes pré-planejados foram avaliados: Cana versus Polpa+Milho e Polpa versus Milho.

\section{RESULTADOS E DISCUSSÃO}

$\mathrm{O} \mathrm{pH}$ ruminal quando os animais foram alimentos de forma restrita no D11 foi ao redor de 7,0 para todos os tratamentos, enquanto os pulsos intrarruminais de concentrado no D12 induziram queda no $\mathrm{pH}$ do fluido (Tab. 3). O valor mínimo de $\mathrm{pH}$ no D12 foi observado três horas após o pulso intrarruminal de polpa cítrica (Fig. 1b), chegando a valores próximos a 5,5. No Milho, apesar de ter sido observada queda no $\mathrm{pH}$ ruminal, este foi sempre superior a 6,0. Mould e Orskov (1983) observaram que a digestão da fibra no rúmen de ovinos foi inibida quando o pH abaixou de 6,8 para 6,0, mas a maior inibição ocorreu quando o $\mathrm{pH}$ foi inferior a 6,0 . Considerando que no D11 houve similaridade entre tratamentos no $\mathrm{pH}$ ruminal e que no D12 este foi inferior nos tratamentos Milho e Polpa, assume-se que o modelo in vivo foi efetivo em simular pH favorável e desfavorável à digestão da fibra no rúmen.

$\mathrm{O} \mathrm{pH}$ ruminal mais baixo no tratamento Polpa reflete a alta fermentabilidade dos carboidratos nesse alimento comparativamente ao amido do milho (Tab. 3). Apesar de o híbrido de milho utilizado não ter sido identificado, o grão tinha textura dura do endosperma. Grãos de milho de textura dura e alta vitreosidade são menos degradados no rúmen que grãos farináceos (Corrêa et al., 2002). Esse fato pode explicar a menor taxa de queda no $\mathrm{pH}$ do fluido ruminal no Milho do que na Polpa, tanto no período de alimentação restrita quanto após os pulsos intrarruminais de concentrados (Fig. 1). A polpa cítrica foi mais indutora de acidose ruminal que o amido de milho maduro finamente moído. 
Efeito do ambiente...

Tabela 3. Amônia (mg/dL) e pH ruminal ao longo de 24h nos dias 11 (D11) e 12 (D12) dos períodos experimentais nos tratamentos Cana, Milho e Polpa

\begin{tabular}{llllllllll} 
& Cana & Milho & Polpa & EPM $^{1}$ & Trat $^{2}$ & Temp $^{2}$ & Trat*Temp $^{2}$ & C vs P+M & P vs M $^{2}$ \\
\hline pH D11 & 7,03 & 7,03 & 6,97 & 0,05 & 0,59 & $<0,01$ & 0,02 & 0,40 & 0,58 \\
pH D12 & 6,98 & 6,49 & 6,04 & 0,14 & $<0,01$ & $<0,01$ & $<0,01$ & 0,05 & $<0,01$ \\
Amônia D11 & 3,4 & 6,2 & 4,4 & 0,5 & 0,01 & $<0,01$ & $<001$ & 0,04 & 0,02 \\
Amônia D12 & 12,6 & 15,0 & 11,3 & 2,0 & 0,44 & $<0,01$ & 0,90 & 0,22 & 0,83
\end{tabular}

${ }^{\mathrm{T}} \mathrm{EPM}=$ Erro-padrão das médias.

${ }^{2}$ Probabilidade para os efeitos de tratamento (Trat), tempo de coleta (Temp), interação entre Trat e Temp e contrastes Cana vs. Polpa+Milho (C vs. P+M) e Polpa vs. Milho (P vs. M).

A concentração ruminal de amônia no D11 foi baixa e teve teor proporcional ao da proteína bruta dietética entre tratamentos (Tab. 1 e 3). O pico de amônia observado três horas após a alimentação (Fig. 1a) seguiu a mesma ordem de grandeza do teor ao longo de $24 \mathrm{~h}$ (Tab. 3). No D11, a concentração ruminal de amônia foi próxima ou inferior à sugerida por Satter e Rofler (1975) para maximização da síntese de proteína microbiana in vitro, em torno de $5 \mathrm{mg} / \mathrm{dL}$ (Tab. 3). Desde que a formação de microambientes em
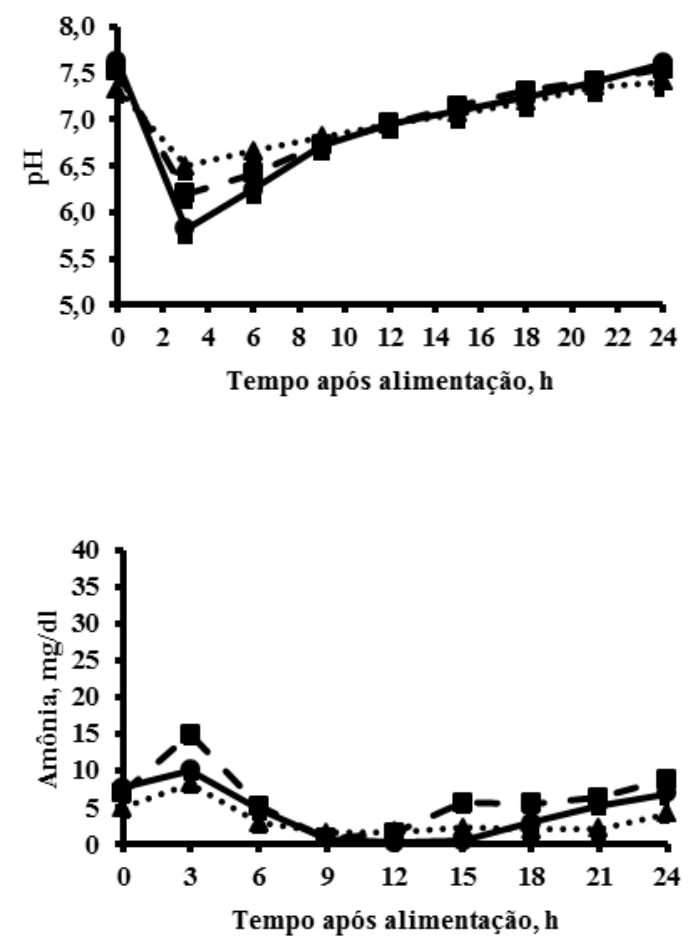

(a) torno de partículas alimentares no rúmen pode resultar em maior necessidade de amônia no fluido ruminal que o necessário para maximização da síntese de proteína microbiana in vitro (Wallace e Cotta, 1988), é provável que tenha ocorrido depressão na capacidade de síntese de proteína microbiana, em alto $\mathrm{pH}$ ruminal, neste experimento. $\mathrm{O}$ alto $\mathrm{pH}$ e o baixo teor de amônia no fluido do rúmen são representativos do perfil fermentativo de bovinos mantidos em baixo plano nutricional.
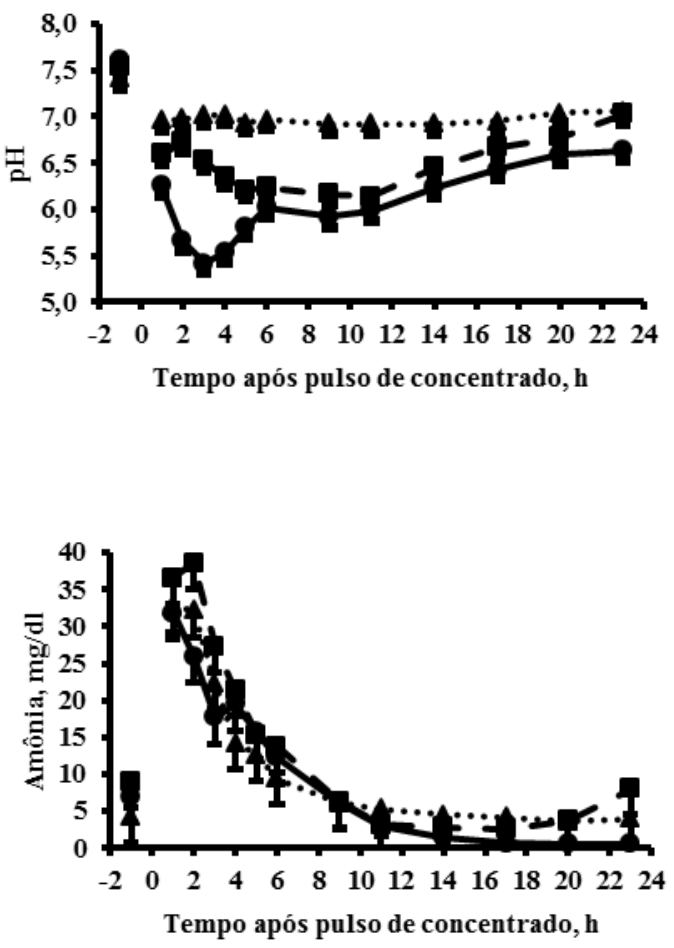

(b)

Figura 1. pH e amônia ruminal após a alimentação no dia 11 do período experimental (a) e após o pulso

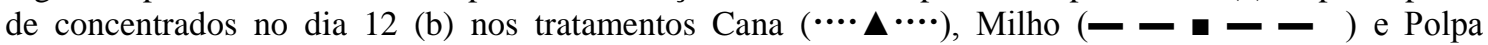


Não foi detectado efeito do perfil de carboidratos dietéticos sobre o teor ruminal de amônia no D12 (Tab. 3, Fig. 1b). Nesse dia, os pulsos intrarruminais de ureia foram capazes de elevar a amônia ruminal nas primeiras nove horas a teores teoricamente não limitantes do crescimento microbiano (Fig. 1b). O pico de amônia observado duas a três horas após o pulso de ureia foi superior ao pico pós-alimentar de vacas de alta produção leiteira consumindo dietas com silagem de alfafa (Pereira e Armentano, 2000). A rápida conversão de ureia em amônia após a introdução do alimento em tempo único no rúmen induziu queda exponencial no teor de amônia ao longo do dia (Fig. 1b), independentemente do tipo de carboidrato fornecido.

A diferença entre a matéria seca degradada em $72 \mathrm{~h}$ e a degradada em $24 \mathrm{~h}$ foi ao redor de $5 \%$ (Tab. 4), refletindo as altas proporções de nutrientes de rápida degradabilidade e de nutrientes indigestíveis nessa forragem (Ezequiel et al., 2005). Houve ganho na DEG FDN quando ureia foi acrescida ao rúmen no tratamento Cana, de alto $\mathrm{pH}$ ruminal, e leve declínio nesse parâmetro quando ureia e concentrados foram infundidos abruptamente no rúmen (Tab. 4). Nos tratamentos Milho e Polpa, o efeito positivo do maior teor de amônia no fluido sobre a atividade fibrolítica foi aparentemente contrabalançado pelo efeito negativo do baixo $\mathrm{pH}$ ruminal (Russell et al., 1990; Grant e Mertens, 1992). A substituição de amido de milho por pectina e fibra de polpa cítrica não reduziu o efeito negativo do baixo $\mathrm{pH}$ e da disponibilidade aguda de carboidratos rapidamente fermentáveis sobre a DEG FDN da cana-de-açúcar (Tab. 4).

A queda na digestão fibrosa em baixo $\mathrm{pH}$ e em presença de alta amônia no rúmen nos tratamentos Milho e Polpa, proporcionalmente ao Cana, foi em torno de $25 \%$ (Tab. 4). Os tratamentos Milho e Polpa também aumentaram o RES 72 relativamente ao Cana. O perfil de carboidratos dietéticos não determinou a DEG FDN no D11, de alto $\mathrm{pH}$ ruminal. O efeito do $\mathrm{pH}$ ruminal foi mais determinante da DEG FDN que o efeito do tipo de substrato fermentativo presente no rúmen. $\mathrm{O}$ tipo e a fermentabilidade dos carboidratos presentes na polpa cítrica (Miron et al., 2002), comparativamente à composição de outros subprodutos fibrosos, podem parcialmente explicar esse fato. A substituição de amido de milho por subprodutos fibrosos oriundos de cereais, em dietas com cerca de $13 \%$ de FDN oriunda de forragens, tendeu a aumentar a degradabilidade da FDN de forragens no rúmen de vacas leiteiras, mesmo sem ter sido detectado efeito sobre o $\mathrm{pH}$ ruminal (Pereira e Armentano, 2000). Pantoja et al. (1994) também reduziram a FDN indigestível de alfafa por adição de casca de soja a uma dieta basal com $15 \%$ de FDN oriunda de forragem. Contudo, a degradabilidade da cana no rúmen no tratamento Polpa foi semelhante à degradabilidade no tratamento Milho (Tab. 4), em um ambiente ruminal mais ácido que o induzido pela dieta com milho (Tab. 3). Algum efeito benéfico da substituição de milho por polpa cítrica pode ter ocorrido, entretanto experimentos envolvendo vacas em produção e com maior consumo são necessários para avaliar essa hipótese.

Tabela 4. Degradabilidade ruminal in situ em 24h de incubação da matéria seca (DEG MS, \% da MS), da FDN (DEG FDN, \% da FDN) e da matéria seca não FDN (DEG MSnFDN, \% da MSnFDN) e resíduo de matéria seca após $72 \mathrm{~h}$ de incubação (RES 72, \% da MS) de 12 cultivares de cana-de-açúcar nos tratamentos Cana, Milho e Polpa nos dias 11 (D11) e 12 (D12) dos períodos experimentais

\begin{tabular}{|c|c|c|c|c|c|c|c|c|c|c|c|c|}
\hline & $\begin{array}{r}\text { C } \\
\text { D11 }\end{array}$ & $\begin{array}{l}\text { Da } \\
\text { D12 }\end{array}$ & $\begin{array}{r}\mathrm{Mi} \\
\mathrm{D} 11\end{array}$ & $\begin{array}{l}\text { lho } \\
\text { D12 }\end{array}$ & $\begin{array}{r}\text { Pol } \\
\text { D11 }\end{array}$ & $\begin{array}{l}\text { lpa } \\
\text { D12 }\end{array}$ & $\mathrm{EPM}^{1}$ & ${ }^{1}$ Trat $^{2}$ & $\mathrm{Amb}^{2}$ & Trat*Amb ${ }^{2}$ & $\begin{array}{c}\text { C vs } \\
\mathrm{P}+\mathrm{M}^{2}\end{array}$ & $\begin{array}{c}\mathrm{P} \text { vs } \\
\mathrm{M}^{2}\end{array}$ \\
\hline$\overline{\text { DEG MS }}$ & 65,0 & 65,1 & 64,3 & 62,9 & 64,7 & 61,4 & 0,49 & 0,01 & $<0,01$ & 0,01 & $<0,01$ & 0,32 \\
\hline DEG FDN & 21,5 & 27,8 & 22,4 & 20,1 & 20,9 & 19,8 & 0,96 & 0,02 & $<0,01$ & $<0,01$ & $<0,01$ & 0,50 \\
\hline DEG MSnFDN & 94,4 & 93,1 & 94,2 & 91,9 & 94,2 & 91,1 & 0,46 & 0,12 & $<0,001$ & 0,58 & 0,12 & 0,16 \\
\hline RES 72 & 28,7 & & 31,5 & & 32,6 & & 0,82 & 0,03 & & & 0,01 & 0,38 \\
\hline
\end{tabular}

${ }^{1} \mathrm{EPM}=$ Erro-padrão das médias.

${ }^{2}$ Probabilidade para os efeitos de tratamento (Trat), ambiente ruminal (Amb), interação entre Trat e Amb e contrastes Cana vs. Polpa+Milho (C vs. P+M) e Polpa vs. Milho (P vs. M). 
Existiu variabilidade entre os cultivares de cana na DEG FDN (Tab. 2). Apesar de a DEG FDN da cana ter sido determinada pelo ambiente ruminal (Tab. 4), o ordenamento dos cultivares por DEG FDN foi similar em ambientes ruminais distintos (Fig. 2). Programas de melhoramento que buscam selecionar cultivares de cana com maior potencial de digestão da fibra podem ser efetivos, mesmo quando a forragem é utilizada em planos nutricionais incompatíveis com a máxima digestão fibrosa.

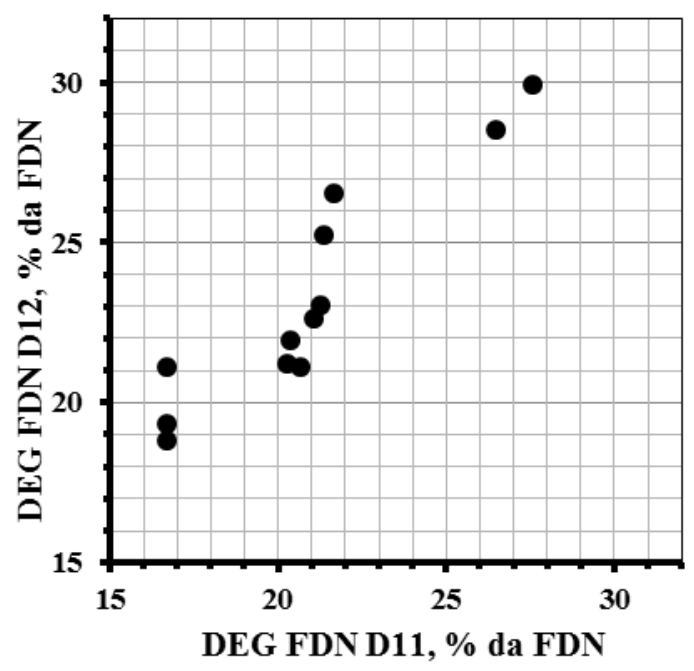

Figura 2. Degradabilidade ruminal in situ da FDN (DEG FDN) de 12 cultivares de cana-de-açúcar nos dias 11 (D11) e 12 (D12) dos períodos experimentais.

\section{CONCLUSÕES}

Ocorreu ganho em digestão fibrosa da cana-deaçúcar em resposta ao aumento no teor de amônia em alto valor de $\mathrm{pH}$ do fluido ruminal. Quando baixo $\mathrm{pH}$ foi induzido experimentalmente, o aumento no teor de amônia no rúmen foi incapaz de elevar a degradabilidade da fibra no rúmen a valores acima dos observados em alto pH e baixa amônia ruminal. A substituição de amido de milho por pectina e fibra de polpa cítrica não foi efetiva na redução da ocorrência de efeitos associativos negativos do ambiente ruminal sobre a degradabilidade da fibra da cana-de-açúcar. O ordenamento de cultivares pela degradabilidade da fibra no rúmen foi similar em ambientes ruminais distintos, o que sugere que a seleção de cultivares com maior potencial de digestão fibrosa não seria afetada pelo plano nutricional adotado.

\section{REFERÊNCIAS}

CHANEY, A.L.; MARBACH, E.P. Modified reagents for determination of urea and ammonia. Clin. Chem., v.8, p.130-132, 1962.

CORRÊA, C.E.S.; PEREIRA, M.N.; OLIVEIRA, S.G. et al. Performance of Holstein cows fed sugarcane or corn silages of different grain texture. Sci. Agr., v.60, p.621-629, 2003.

CORREA, C.E.S.; SHAVER, R.D.; PEREIRA, M.N. et al. Relationship between corn vitreousness and ruminal in situ starch degradability. J. Dairy Sci., v.85, p.3008-3012, 2002.

EZEQUIEL, J.M.B.; QUEIROZ, M.A.A.; GALATI, R.L. et al. Processamento da cana de açúcar: efeito sobre a digestibilidade, o consumo e a taxa de passagem. Rev. Bras. Zootec., v.34, p.1704-1710, 2005.

GRANT, R.J.; MERTENS, D.R. Influence of buffer $\mathrm{pH}$ and raw corn starch addition on in vitro fiber digestion kinetics. J. Dairy Sci., v.75, p.2762-2768, 1992. 
MAROUNEK, M.; BARTOS, S.; BREZINA, P. Factors influencing the production of volatile fatty acids from hemicellulose, pectin and starch by mixed culture of rumen microorganisms. $Z$. Tierphysiol. Tierernahr. Futtermittelkd., v.53, p.50-58, 1985.

MIRON, J.; YOSEF, E.; BEN-GHEDALIA, D. et al. Digestibility by dairy cows of monosaccharide constituents in total mixed rations containing citrus pulp. J. Dairy Sci., v.85, p.89-94, 2002.

MOLINA, A.; LEAL, P.P.; VERA, A. et al. Forage evaluation of sugar cane industrial varieties: in situ digestibility. Cub. J. Agric. Sci., v.33, p.369-373, 1999.

MOULD, F.L.; ORSKOV, E.R. Manipulation of rumen fluid $\mathrm{pH}$ and its influence on cellulolysis in sacco, dry matter degradation and the rumen microflora of sheep offered either hay or concentrade. Anim. Feed Sci. e Thechnol., v.84, p.1-14, 1983.

OSBORNE, J.M.; DEHORITY, B.A. Synergism in degradation and utilization of intact forage cellulose, hemicellulose, and pectin by three pure cultures of ruminal bacteria. Appl. Environ. Microbiol., v.55, p.2247-2250, 1989.

OFFICIAL methods of analysis. 15.ed. Washington, DC: AOAC, 1990. v.1, 1117p.

PANTOJA, J.; FIRKINS, J.L.; EASTRIDGE, M.L. et al. Effects of fat saturation and source of fiber on site of nutrient digestion and milk production by lactating dairy cows. J. Dairy Sci., v.77, p. 2341-2356, 1994.
PATE, F.M. Fresh chopped sugar cane in growing - finishing steer diets. J. Anim. Sci., v.53, p.881-888, 1981

PATE, F.M.; COLEMAN, S.W. Evaluation of sugar cane varieties as cattle feed. Flórida: University of Fla., n.4, 1975. 8p.

PEREIRA, M.N.; ARMENTANO, L.E. Partial replacement of forage with nonforage fiber sources in lactating diets. II. Digestion and rumen function. J. Dairy Sci., v.83, p.2876-2887, 2000 .

RUSSELL, J.B.; STROBEL, H.J.; MARTINS, S.A. Strategies of nutrient transport by ruminal bacteria. J. Dairy Sci., v.73, p.2996-3012, 1990.

SATTER, L.D.; ROFLER, R.E. Nitrogen requirement and utilization in dairy cattle. $J$. Dairy Sci., v.58, p.1219-1237, 1975.

TEIXEIRA, C.B.; RAMOS, M.H.; SANTOS, J.F. et al. Variáveis agronômicas e químicas e degradabilidade ruminal da cana-de-açúcar. Arq. Bras. Med. Vet. Zootec. (no prelo)

VAN SOEST, P.J.; ROBERTSON, J.B.; LEWIS, B.A. Methods for dietary fiber, neutral detergent fiber, and nonstarch polysaccharides in relation to animal nutrition. J. Dairy Sci., v.74, p.35833597, 1991.

WALLACE, R.J.; COTTA, M.A. Metabolism of nitrogen-containing compounds. In: Hobson, P.N. The rumen microbial ecosystem, London: Elsevier, 1988. p.217-249. 